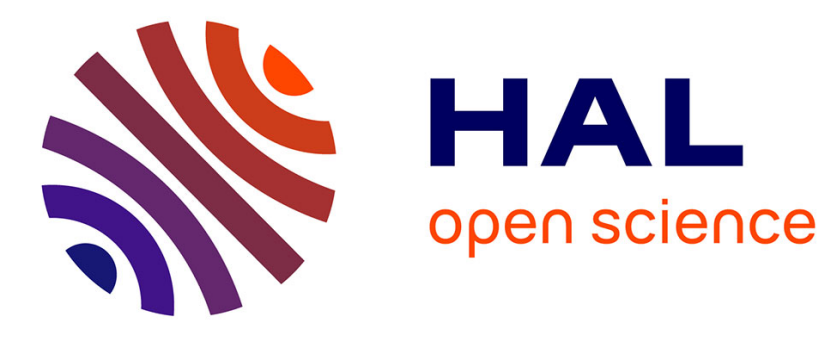

\title{
Electric dipolar echoes in glasses
}

\author{
L. Bernard, L. Piche, G. Schumacher, J. Joffrin, J. Graebner
}

\section{To cite this version:}

L. Bernard, L. Piche, G. Schumacher, J. Joffrin, J. Graebner. Electric dipolar echoes in glasses. Journal de Physique Lettres, 1978, 39 (9), pp.126-129. 10.1051/jphyslet:01978003909012600 . jpa00231459

\section{HAL Id: jpa-00231459 https://hal.science/jpa-00231459}

Submitted on 1 Jan 1978

HAL is a multi-disciplinary open access archive for the deposit and dissemination of scientific research documents, whether they are published or not. The documents may come from teaching and research institutions in France or abroad, or from public or private research centers.
L'archive ouverte pluridisciplinaire HAL, est destinée au dépôt et à la diffusion de documents scientifiques de niveau recherche, publiés ou non, émanant des établissements d'enseignement et de recherche français ou étrangers, des laboratoires publics ou privés. 
Clasisification

Physics Abstracts

$60.40 \mathrm{D}-71.55-77.90$

\title{
ELECTRIC DIPOLAR ECHOES IN GLASSES
}

\author{
L. BERNARD, L. PICHE, G. SCHUMACHER \\ C.R.T.B.T., C.N.R.S., B.P. 166, Centre de Tri, 38042 Grenoble, France
}

J. JOFFRIN

I.L.L. $\left({ }^{*}\right)$. Grenoble: ( .R.T.B.T. $\left({ }^{* *}\right)$. C.N.R.S.. B.P. 166. Centre de Trı, 38042 Grenoble, France

and J. GRAEBNER

Bell Laboratories, Murray Hill, New Jersey 07974, U.S.A.

(Reçu le ler février 1978, accepté le 13 mars 1978)

\begin{abstract}
Résumé. - On décrit des expériences d'échos électriques dipolaires dans des verres contenant des impuretés ioniques $\mathrm{OH}^{-}$. Ces expériences sont réalisées dans la gamme de température 3 à $20 \mathrm{mK}$ et à une fréquence de $370 \mathrm{MHz}$. Les échos spontanés et stimulés sont observés et leurs caractéristiques en fonction de la température et de l'amplitude des impulsions appliquées sont relevées. En supposant que les dipoles électriques ont deux niveaux d'énergie, on déduit des mesures des valeurs indépendantes pour leur moment dipolaire, leur densité d'état et leur couplage avec les déformations élastiques.
\end{abstract}

\begin{abstract}
Electric dipolar echoes are observed in $\mathrm{OH}^{-}$doped vitreous silica in the 3 to $20 \mathrm{mK}$ range at a frequency of $370 \mathrm{MHz}$. We study the behaviour of both spontaneous and stimulated echoes, their dependence on the input pulse amplitude and their decay in time. Assuming the existence of a two level $\mathrm{OH}^{-}$dipole moment we deduce by independent measurements its effective value and density of states; we also evaluate the elastic coupling between these defects and the phonons.
\end{abstract}

1. Introduction. - At low temperature, nearly all glasses show anomalous properties : the specific heat is high and obeys a law in temperature $(T)$ which is linear [1]; the thermal conductivity is small and proportional to $T^{2}[1]$; the acoustic attenuation can be saturated [2]. All these properties can be understood by assuming that configuration defects, intrinsic to the glass, exist having at least two degrees of freedom (TLS), with a broad distribution of energy splittings and that they are strongly coupled to the phonon field [3]. Further evidence is given to support these ideas by the anomalous behaviour of the sound velocity which varies like $\log T$ [4].

When the glass has a certain content of ionic molecules (such as $\mathrm{OH}^{-}$), its dielectric constant varies with temperature and has the same $\log T$ dependence [5]. This implies that at least part of the ionic molecules have, like the intrinsic TLS, a broad excitation spectrum. Moreover, experiments performed by crossing

(*) Par devoir.

(**) Par plaisir an electromagnetic and an acoustical wave $[6,7]$ have shown that some of the ionic molecules behave as if they were associated with intrinsic TLS. Even though the nature of the binding is unknown, we can say that the ions act as markers for part of the TLS : they seem to reproduce their distribution.

The dynamics of the TLS may be described like those of a spin $1 / 2$ assembly : $T_{1}$ is a time needed for the disturbed population to return to thermal equilibrium and $T_{2}$ is a phase memory time. This concept was evidenced mainly by making use of the ultrasonic technique [8]. Quite recently, $T_{1}$ and $T_{2}$ for the intrinsic TLS were measured in a straightforward way by performing acoustic echoes experiments [9]. In order to study the dynamic properties of the $\mathrm{OH}^{-}$ defects we would like to report some measurements done by performing electric dipolar echoes at very low temperature.

For this, we make use of the fact that the $\mathrm{OH}^{-}$ions are easily coupled to an external electrical field : we apply an R.F. electrical pulse to the electrodes attached on a thin disk of Suprasil I glass [10] containing $1200 \mathrm{ppm} \mathrm{OH}^{-}$ions; there is a resonant inter- 
action with those $\mathrm{OH}^{-}$molecules which have an energy splitting that lies within the bandwidth of the pulse. The population of these defects is coherently excited by this first pulse. Because the defects may interact with their environment (thermal phonons, other defects...) this state evolves in a partly coherent, and partly incoherent way. A second pulse applied after a time $\tau$ restores an echo at time $2 \tau$ whose amplitude is affected only by the irreversible evolution of the system : we observe a spontaneous dipolar electrical echoe. We then monitor its amplitude as a function of $\tau$ and temperature. The magnitude of the spontaneous echo is a measure of $T_{2}$ and that of the stimulated echo, obtained in a sequence of three pulses, is a measure of $T_{1}$.

2. Experimental set-up. - The sample is made up from two disks of Suprasil I glass $(10 \mathrm{~mm}$ in diameter and $1 \mathrm{~mm}$ in thickness) to which superconducting electrodes are attached. The disks are then clamped together and make up the capacitor $(\simeq 2 \mathrm{pF})$ in a resonant eircuit tuned at $3.70 \mathrm{MHz}$ and matched to the $50 \Omega$ characteristic impedance of the line. At low temperature, the $Q$ of the circuit is 300 .

The ensemble is immersed in the dilute phase of the mixing chamber of our dilution refrigerator [11]. The runs were done in the range from $3 \mathrm{mK}$ to $30 \mathrm{mK}$ and - for each set of data - the temperature, measured with a C.M.N. thermometer was stabilized to $1 \%$ for many days. We took care at all times to reduce the average R.F. power delivered to the sample to a value far below that at which any heating effect was observed either on the C.M.N. or on the echo signal.

This compelled us to use very low repetition rates : $0.5 \mathrm{~Hz}$ at our lowest temperature of $3.8 \mathrm{mK}$. Our measurements were done at an R.F. frequency of $370 \mathrm{MHz}$ with pulses 0.7 and $1.4 \mu$ s wide. The peak pulse power sent to the sample ranged from $-45 \mathrm{dBm}$ to $-10 \mathrm{dBm}$. The detector is sensitive to roughly $-100 \mathrm{dBm}$; it is calibrated such that $0 \mathrm{~dB}$ corresponds to a signal of $-76 \mathrm{dBm} \pm 1$. The insertion losses of the coaxial line is $3 \mathrm{~dB}$ one way between the generator and the sample.

3. Experimental results. -3.1 Our results on the study of the magnitude of the spontaneous echo versus the input pulse power are shown in figure 1. The two pulses have equal amplitudes but the second, $\pi$ pulse, is twice as wide $\left(\Delta t_{2}=1.4 \mu \mathrm{s}\right)$ as the first $\pi / 2$ pulse $\left(\Delta t_{1}=0.7 \mu \mathrm{s}\right)$; they are separated from one another by a time $\tau=5 \mu$ s so that the echo appears at time $2 \tau=10 \mu \mathrm{s}$.

At low enough temperature, as the input power is increased, the signal follows a cube law and then goes through a maximum. This behaviour is characteristic of the case of spin echo so that we can identify the maximum with a rotation of $\pi / 2$ of the polarization. As the temperature becomes higher, we observe

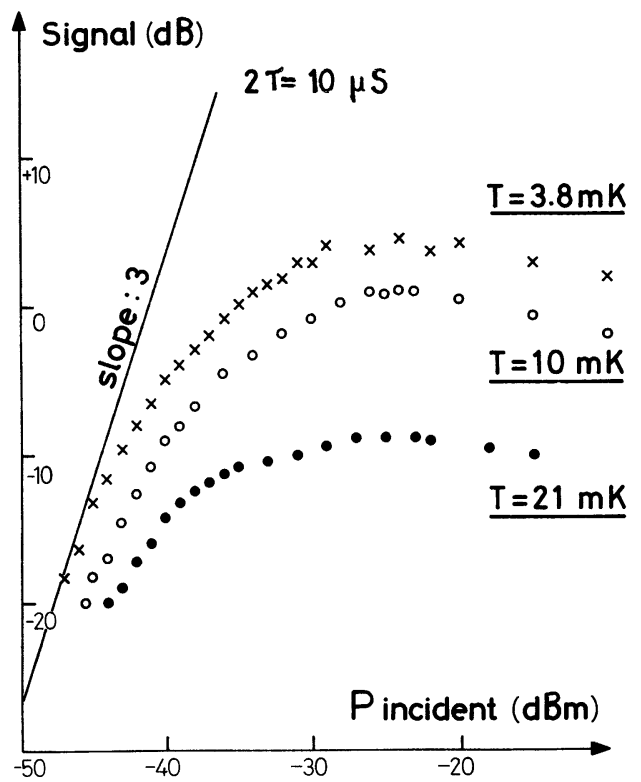

Fig. 1. - Variation of the amplitude (power) of the spontaneous echo with the incident pulse power $P$; the time interval between the $\pi / 2$ and $\pi$ pulse $\tau=10 \mu$ is constant. For clarity, only results at temperatures $T=3.8,10$ and $21 \mathrm{mK}$ are shown. The full line is drawn to compare with theoretical $P^{3}$ dependence in the low power limit.

only the upper part of the curve, the signal becoming too small.

At the position of the maximum we can estimate the electrical field accross the sample from the characteristics of the resonance circuit : $E_{\max }=130 \pm 10 \mathrm{~V} / \mathrm{m}$; we thus calculate the effective value $\bar{p}$ for the $\mathrm{OH}^{-}$ dipole moment with the following formula :

$$
\bar{p} E_{\max } \Delta t_{1}=\frac{\pi}{2} \hbar \text {. }
$$

We find $\bar{p}=1.8 \times 10^{-30}$ MKS or 0.5 Debye; this is relatively small compared to 1.9 Debye for the free water molecule but in agreement with other estimates.

3.2 The amplitude of the polarization within the sample can be written when the signal is at its maximum and for the limiting condition $\tau=0$

$$
\mathfrak{T}=n_{0} \hbar \Delta \omega \bar{p} \text { th }(\hbar \omega / 2 k T) .
$$

$n_{0}$ is the density of states of the dipoles which we assume to be broad and flat; $\omega$ is the RF angular frequency and $\Delta \omega=\pi / 2 \Delta t_{1}$ is the bandwidth of the dipoles which are excited. The term th $(\hbar \omega / 2 k T)$ is the population factor which expresses the temperature dependence of $\mathcal{T}$. Finally : $\mathcal{T}=\varepsilon_{0} E_{\mathrm{loc}}$ and $E_{\text {loc }}$ is itself deduced from the detected signal.

We have checked that equation (2) is well verified in our temperature range; also from (2), we can estimate $n_{0}$ the density of defects having an energy splitting of the order of $\hbar \omega(370 \mathrm{MHz} \equiv 18 \mathrm{mK})$ by using the value of $\bar{p}$ obtained from (1). For this, 
considering the curve at $3.8 \mathrm{mK}$, we see that the maximum output signal is $-66 \mathrm{dBm}$ (extrapolated to $\tau=0$ ); for an estimated $3 \mathrm{~dB}$ loss in the line this corresponds to $\mathcal{T}=2.9 \times 10^{-14} \mathrm{MKS}$; then

$$
n_{0}=7 \times 10^{43} \mathrm{MKS}=7 \times 10^{30} \mathrm{erg}^{-1} \mathrm{~cm}^{-3} .
$$

This number is to be compared with the value $10^{32} \mathrm{erg}^{-1} \mathrm{~cm}^{-3}$ obtained from specific heat data [1] which includes both the contribution of the intrinsic and $\mathrm{OH}^{-}$defects. We can thus say that the $\mathrm{OH}^{-}$ions have a density roughly equal to $7 \%$ of the TLS in the energy range explored. This is small compared to the value of $50 \%$, estimated from other experiments [1]. On the other hand, the quantity $n_{0} \bar{p}^{2}$ deduced from the variation of the dielectric constant at low temperatures [5] is $n_{0} \bar{p}^{2}=8 \times 10^{-15} \mathrm{MKS}$. If we calculate the same factor by using the values of $n_{0}$ and $\bar{p}$ which we measure independently, we find $n_{0} \bar{p}^{2}=2 \times 10^{-16}$, our value is much smaller; this would tend to prove that the density $n_{0}$ decreases with energy, a result already suspected but not yet proved.

3.3 In order to describe the behaviour of the spontaneous echo, we have plotted in figure 2 the intensity of the echo signal as a function of $2 \tau$ ( $\tau$ is the time interval between the first and the second pulse) for different power values of the exciting pulses. In figure 2 the temperature is kept constant and equal to $3.8 \mathrm{mK}$; we obtain similar sets of data at other temperatures.

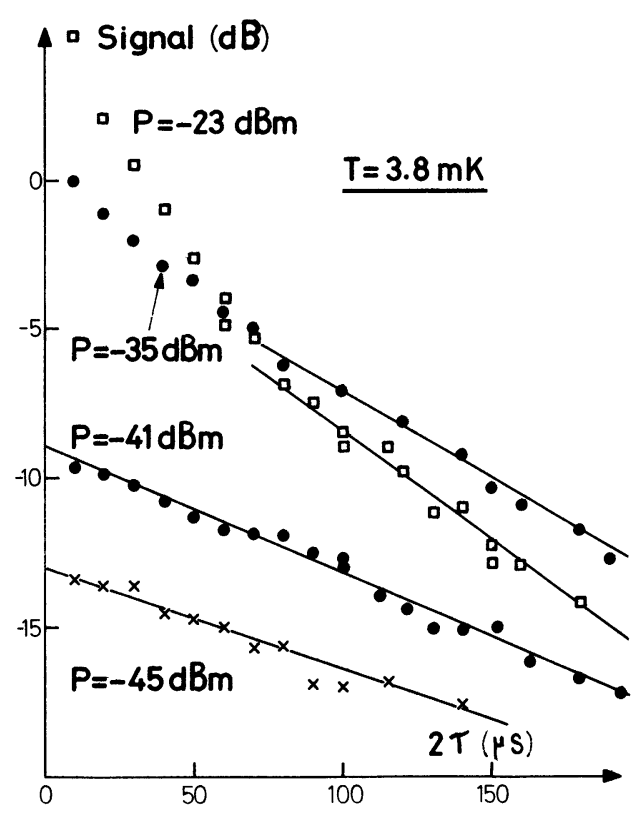

FIG. 2. - Amplitude decay of spontaneous echo with time interval $\tau$ between $\pi / 2$ and $\pi$ pulse. The results at the fixed temperature $T=3.8 \mathrm{mK}$ are shown for different values of the incident power $P$. The slopes of the full lines are a measure of the memory time $T_{2}$.

First, we see that there is a strong power dependence of the slopes which should give us the value of $T_{2}$ : for the lowest value of $P=-45 \mathrm{dBm}$ (corresponding to the asymptotic $P^{3}$ regime of figure 1), $T_{2}$ is of the order of $250 \pm 10 \mu \mathrm{s}$; it decreases to be as short as $50 \mu$ s when $P=-23 \mathrm{dBm}$ (corresponding to the maximum of the echo signal). Before any explanation of this behaviour can be given, more systematic data have to be collected. We may also notice on figure 2 that, especially for the high power values, the signal does not show an exponential decay as a function of $\tau$ but is curved as if there was a distribution of relaxation times, or as if diffusion was present. Here also a more detailed analysis has to be made.

Finally, when compiling all our data for low power regimes and different temperatures where a single relaxation time can be defined, we find a temperature dependence for $T_{2}$ which is near that of a $T^{-1}$. This seems to rule out the existence of a process which would give a $T^{-2}$ law [12].

3.4 Turning now to the measurements of the stimulated, or three pulse echo, our results are shown on figure 3 where we have plotted the power amplitude of the echo as a function of $T$, the time between the second and third pulse. The duration and power of all three pulses are the same, $0.6 \mu$ s and the time between the first and second is held constant at $2.5 \mu \mathrm{s}$.

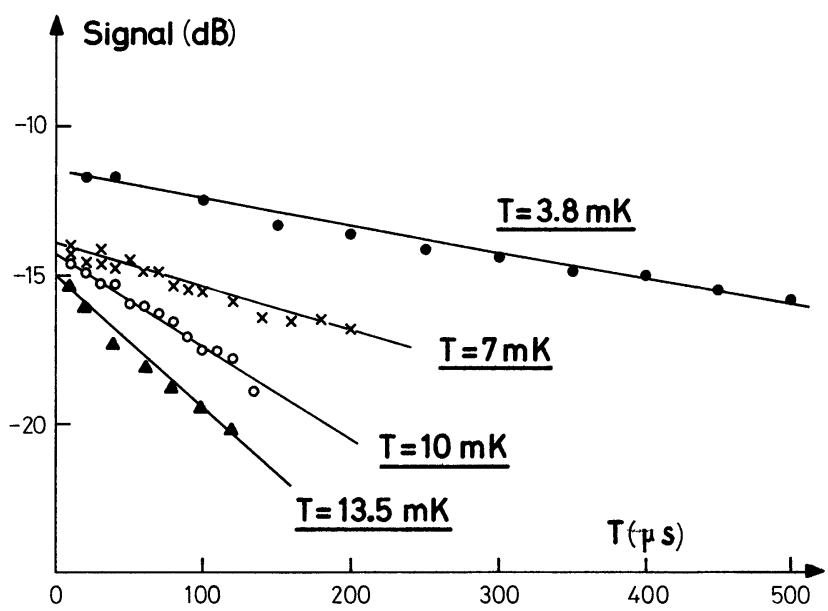

Fig. 3. - Amplitude decay of the stimulated echo versus time interval $T$ between second and third pulse, at different temperatures. The input pulse power is held constant at the minimum value of $P=-45 \mathrm{dBm}$. The slopes of the full lines are a measure of $T_{1}$.

Here we show our results for $T_{1}$ measured at different temperatures each time in the lowest measurable power regime. The interesting features are : the signal does not show a purely exponential decay; in fact, as in the case of $T_{2}$, we have observed that $T_{1}$ depends on the incident power. From our results for low values of power, we find that $T_{1}$ obeys a $T^{-1}$ temperature law. This is a good indication that the $T_{1}$ can be described by a one phonon relaxation process. In such a case, the relaxation time $T_{1}(E)$ of a two level defect with energy splitting $E$ is given [13] by :

$$
T_{1}^{-1}(E)=\left(\frac{M_{1}^{2}}{c_{1}^{5}}+\frac{2 M_{\mathrm{t}}^{2}}{c_{\mathrm{t}}^{5}}\right) \frac{E^{3}}{2 \pi \rho \hbar^{4}} \operatorname{coth} \frac{E}{2 k T}
$$


where $\rho=2.2 \times 10^{3} \mathrm{MKS}$ is the density; the indices 1 and $\mathrm{t}$ refer to the longitudinal and transverse polarizations of the phonons. If we admit that the transverse component dominates the process, with

$$
c_{\mathrm{t}}=3.6 \times 10^{3} \mathrm{~m} \cdot \mathrm{s}^{-1}
$$

we obtain, for $T_{1}^{-1}=860 \mu \mathrm{s}$ at $T=3.8 \mathrm{mK}$, $M=1.2 \mathrm{eV}$. This is large in comparison with intrinsic TLS [4] but not surprising if we think of the same ionic molecules imbeded in single crystals [14].

4. Conclusion. - In summary, we have been able to independently estimate $\bar{p}$, the effective electrical dipole moment which we suppose associated with the $\mathrm{OH}^{-}$impurities in Suprasil I glass, $n_{0}$, the density of states of these defects and $M$ their coupling constant to the strain field. We have also measured directly $T_{1}$ and $T_{2}$, as a function of temperature, and shown that both are linear functions of $T^{-1}$ in the low power limit. Our experiment was performed at unusually low temperatures and our results concern solely $\mathrm{OH}^{-}$ marked TLS; we can say that the numerical values which we obtain do not fall exactly in the range that could be expected : $M$ for instance is large : three times the value of the intrinsic TLS ; concerning $T_{1}$, we can conclude that the description can be made through the one phonon relaxation process, as for $T_{2}$, the general non exponential behaviour suggests the existence of more than one mechanism. Here more data is still needed and a more complete analysis has to be made.

We can however think that the anomalous power dependence observed for $T_{1}$ and $T_{2}$ can be attributed to the special problem of a glass where the population of dipoles is very broad and inhomogeneous, and where the dipoles interact strongly with each other. These aspects will be treated in a further and more complete publication.

\section{References}

[1] Lasjaunias, J. C., Ravex, A., Vandorpe, M., Hunklinger, S., Solid State Commun. 17 (1975) 1045.

[2] Arnold, W., Hunklinger, S., Stein, S., Dransfeld, K., J. Non-Cryst. Solids 14 (1974) 192.

[3] Anderson, P. W., Halperin, B. I., Varma, C. M., Philos. Mag. 25 (1972) 1.

Phillips, W. A., J. Low Temp. Phys. 7 (1972) 351.

[4] Piche, L., Maynard, R., Hunkuinger, S., Jäckle, J., Phys. Rev. Lett. 32 (1974) 1426.

[5] Schickfus, M. V., Hunklinger, S., Piche, L., Phys. Rev. Lett. 35 (1975) 876

[6] Laermans, C., Arnold, W., Hunklinger, S., J. Phys. C 10 (1977) L-161.

[7] Doussineau, P., Levelut, A., Ta, T.-T., J. Physique Lett. 38 (1977) 37.

[8] Bachellerie, A., Doussineau, P., Levelut, A., TA, T.-T., J. Physique 38 (1977) 69.

Joffrin, J., Levelut, A., J. Physique 36 (1975) 811.
[9] Golding, B., Graebner, J. E., Phys. Rev. Lett. 37 (1976) 852.

[10] Suprasil I samples where obtained from Heraeus-France, and contain less than $0.5 \mathrm{ppm}$ metallic ions and about $1200 \mathrm{ppm} \mathrm{OH}^{-}$ions.

[11] Schumacher, G., Thèse d'Etat Réfrigération par dilution de ${ }^{3} \mathrm{He}$ dans le ${ }^{4} \mathrm{He}$ dans la région du millikelvin Grenoble. avril 1978.

[12] Black, J. L., Ph. D Thesis, Harvard University, Cambridge, Massachusetts (1977);

Black, J. L., Halperin, B., Phys. Rev. B 16 (1977) 2879.

[13] Jä́ckle, J., Piche, L., Arnold, W., Hunklinger, S., J. NonCryst. Solids 20 (1976) 365.

[14] Narayanamurthi, V., Pohl, R. O., Rev. Mod. Phys. 42 (1970) 201. 